\title{
Коблева А.Л. \\ Развитие психологической культуры педагога как условие качества современного образования
}

Ставропольский государственный педагогический институт

(Россия, Ставрополь)

doi: 10.18411/trnio-12-2021-135

\section{Аннотация}

В статье рассмотрены условия развития психологической культуры педагога как одного из первостепенных условий обеспечения качества образовательной среды, обеспечивающих гармонизацию субъектов образовательных отношений. Психологическая культура педагога рассматривается как интегральное качество личности необходимое для гармонизации отношений межу субъектами образовательной среды. Определена роль педагога в современном образовании как носителя и проектировщика психологической культуры.

Ключевые слова: педагог, психологическая культура педагога, здоровьецентризм, эмоциональное выгорание.

\section{Abstract}

The article considers the conditions for the development of the psychological culture of a teacher as one of the primary conditions for ensuring the quality of the educational environment, ensuring the harmonization of subjects of educational relations. The psychological culture of a teacher is considered as an integral quality of personality necessary for the harmonization of relations between the subjects of the educational environment. The role of the teacher in modern education as a carrier and designer of psychological culture is determined.

Keywords: teacher, psychological culture of the teacher, health-centrism, emotional burnout.

На сегодняшний день в условиях модернизации системы непрерывного образования особенно остро обозначена проблема развития психологической культуры педагога с целью укрепления социально-психологической безопасности образовательной среды.

Изучение вопроса психологического здоровья имеет многолетнюю историю. Так, в 1992 году в модели обусловленности здоровья были выделены основные определяющие его состояние факторы, которые и сегодня не утратили своей значимости: образ жизни - 50-55\%, внешнее окружение (среда) - 20-25\%, генетические особенности - 15-20\%, система здравоохранения - $10 \%$ [8].

По мнению В.А. Ананьева, если человек научится осознавать и контролировать свое поведение, эмоции, мысли, то он может научиться полноценно жить и развиваться, успешно гармонизировать отношения с миром [1, С.8].

Учитывая тот факт, что современное общество особенно строго оценивает личностные и профессиональные качества педагога, такие, как социальная ответственность, интеллектуальное совершенство, моральная чистота и др. вопрос о сохранении и укреплении здоровья участников образовательного процесса выделен государством в качестве общенационального. На сегодняшний день, Н.А. Аминов выявил среди педагогов с высшей категорией 53\% эмоционально выгоревших. Кроме того, у них отмечается высокая степень тревожности и интровертированности. При этом, у эмоционально выгоревших педагогов с низким уровнем квалификации обнаружены высокая агрессия и ярко выраженное стремление к доминированию (контролю над ситуацией). Обобщение и анализ результатов исследования, как отмечает Н.А. Аминов, продемонстрировали высокую вероятность развития синдрома эмоционального выгорания к 40 годам, т.е. после 20 лет непрерывного педагогического стажа [2]. 
Проведенный Е.Э. Кригером анализ многочисленных исследования факторов педагогической деятельности, которые приводят к возникновению неврозов и психосоматической патологии у 70-90\% педагогов заставляет всерьез задуматься о необходимости развития психологической культуры в образовательном пространстве [7].

Психологическая культура - это психологическая образованность человека, в сочетании с готовностью и умением использовать ее в повседневной жизни с целью самопознания, повышения эффективности общения и самосовершенствования. Как отмечает Л.С. Колмогорова, психологическая культура определяет уровень психологической грамотности - совокупности психологических знаний и умений, которые человек усваивает в определенном возрасте с учетом индивидуальных особенностей. Психологическая грамотность проявляется в осведомленности, как с научной точки зрения, так и с точки зрения житейского опыта. Важнейшим условием является не только овладение системой знаний, но и их применение [6].

В работах И.В. Дубровиной понятие психологической культуры раскрывается как реализация психологических знаний в обществе, которая осуществляется с гуманистических позиций уважения, любви, совести, ответственности, бережного отношения к чувству личного достоинства как своего, так и другого человека [3].

Социальная незащищенность педагогов, говоря словами Ю.М. Забродина, делают необходимым создание национальной системы психологического сопровождения и поддержки индивида на его жизненном пути, прежде всего, в процессе формирования и реализации профессиональной карьеры человека $[4, \mathrm{C} .5]$.

Многочисленные рассуждения о личностно-ориентированном подходе к управлению человеческими ресурсами в системе образования характеризуются аддитивным подходом к рассмотрению личности педагога, а именно рассматривает отдельно взятые личностные и профессиональные характеристики, составляющие его компетентность, этого недостаточно. Нужен интегративный подход, обеспечивающий осознание взаимодействия тех или иных показателей профессиональной компетентности педагога, что в результате позволит реализовать принцип здоровьецентризма, который предполагает ориентацию участников образовательного процесса на здоровье как базисную ценность и один из ключевых результатов деятельности [5].

Именно способ организации взаимодействия участников образовательного процесса является той фундаментальной исходный точкой, откуда начинается путь развития психологической культуры и «профессионального» здоровья педагога.

Идея развития психологической культуры современного педагога, осуществляющего миссию человека культуры, раскрывается через следующие положения:

социально-психологическое предназначение педагогической деятельности предопределяет глубокое осознание педагогом, прежде всего, своей изначальной, профессиональной принадлежности, причастности к культуре. По существу, выполняемой миссии педагог находится в русле тех общественных, социокультурных процессов, которые связаны с человекосозиданием;

- выступая в качестве субъекта здоровьесозидающей деятельности, педагог, как носитель программ будущего должен быть способен к психической саморегуляции, как одной из ключевых критериев сформированности психологической культуры;

поскольку, в современных условиях, миссия созидания психологического здоровья субъектов образовательного процесса ложится непосильным грузом на плечи нередко соматически ослабленного, эмоционального «выгоревшего» педагога, здоровьесозидающая профессиональная деятельность требует ресурсной обеспеченности и защищенности.

Все выше изложенное позволяет констатировать, что успешность профессиональных результатов, обусловлена индивидуально-психологическим ресурсным потенциалом 
педагога, определяющим уровень его психологической культуры. И если сегодня, мы полагаем, что качество образования - это образование на протяжении всей жизни, то, и развитие психологической культуры педагога, тоже должно фокусироваться в изменяющихся характеристиках образовательной среды [5].

$$
* * *
$$

1. Ананьев, В. А. Основы психологии здоровья. Книга 1. Концептуальные основы психологии здоровья. СПб.: Речь, 2006. - 384 с., с 8.

2. Аминов, Н. А. Психофизиологические и психологические предпосылки педагогических способностей / Н. A. Аминов // Вопросы психологии. - 1988. - № 5. - С. 71-77.

3. Дубровина Ирина Владимировна Психологическая культура личности как феномен // Вестник Мининского университета. 2013. №1 (1).

4. Забродин, Ю.М., Зазыкин, В.Г., Зотова, О.И. и др. Проблемы психологии труда и профессии /Ю.М. Забродин, В.Г. Зазыкин, О.И. Зотова//Психологический журнал, М.: Педагогика, 1981, №2, с. 4-7.

5. Коблева, А. Л. Профессиональная рефлексия как условие развития современного педагога // Я-концепция субъекта образовательной среды высшей школы: Материалы Всероссийской научно-практической конференции с международным участием, Ставрополь, 30 ноября 2017 года. - Ставрополь: Ставропольский государственный медицинский университет, 2017. - С. 129-133.

6. Колмогорова, Л. С. Психологическая культура и психическое здоровье в обществе и образовании / Л. С. Колмогорова // Культура Алтайского края как опыт толерантного взаимодействия сопредельных территорий: Международная научно-практическая конференция, посвященная 70-летию Алтайского края края, Барнаул, 23-25 мая 2007 года. - Барнаул: Алтайский государственный аграрный университет, 2007. - С. 363-365.

7. Кригер Е. Э. Профессионально-психологические риски здоровья педагогов // MHКО. 2012. №3. URL: https://cyberleninka.ru/article/n/professionalno-psihologicheskie-riski-zdorovya-pedagogov (дата обращения: 19.11.2021).

8. Лисицын, Ю.П. Детерминационная теория медицины: Доктрина адаптив. реагирования / Ю. П. Лисицын, В. П. Петленко. - СПб.: Гиппократ, 1992. - 414 с.

\section{Медведева А.О., Редников Д.В. \\ Психологические особенности поведения вооружённого человека}

Башкирский государственный университет

(Россия, Уфа)

doi: 10.18411/trnio-12-2021-136

\section{Аннотация}

Целью статьи является анализ поведения человека, имеющего оружие. Дается сравнение военнослужащего с человеком, использующим оружие не по тривиальному назначению. В результате выделены мотивы приобретения оружия и охарактеризована психологическая основа каждого из них.

Ключевые слова: оружие, психологические аспекты поведения вооруженного человека, поведение в военном конфликте.

\section{Abstract}

The purpose of the article is to analyze the behavior of a person who has a weapon. A comparison is made between a serviceman and a person who uses weapons for a non-trivial purpose. As a result, the motives for acquiring weapons are highlighted and the psychological basis of each of them is characterized.

Keywords: weapon, psychological aspects of the armed man, behavior in military conflict.

Испокон веков человечество изобретает и совершенствует оружие. Раньше это был камень и палка - примитивные предметы для защиты от нападения хищников, а позже для охоты. С развитием общества развиваются и методы контроля и управления им с помощью оружия, помимо использования его в военных целях. 